\title{
Determination of the dynamic performance of natural viscoelastic composites with different proportions of reinforcing fibers
}

https://doi.org/10.1515/cls-2022-0011

Received Oct 15, 2021; accepted Jan 19, 2022

\begin{abstract}
Viscoelastic composites are strong and handle vibration damping quite well, which allows them to be used in a wide variety of applications. Thus, there is a need to determine the optimal amount of fiber to ensure high mechanical and dynamic performance with as little interference as possible. The purpose of this work is to find the most appropriate percentage of organic fiber - cellulose derived from corn stalks in a polylactic acid matrix, studying the changes in damping characteristics, tensile strength, bend-test. As parameters for comparison, the coefficient of bending and breaking strength, modules of accumulation and losses, factor $C$ were chosen. It was found that strength indicators decrease with fiber fraction growth. While the damping factor at the glass transition temperature increases. In order to confirm the results obtained, the calculation of the $C$ factor was used. The study investigates the damping factor's dependence on the mechanical properties. It is shown that there is a correlation between moduli and bending strength with increasing fiber fraction. The scientific novelty of this work is the study of natural viscoelastic composites with different proportions of reinforcing fibers based on mechanical and dynamic characteristics in order to create and apply biodegradable viscoelastic composites in various fields.
\end{abstract}

Keywords: cellulose fiber, viscoelastic composites, biodegradable materials, evaluating, damping factor

\footnotetext{
*Corresponding Author: Rodion Rogulin: Department of Mathematics and Modelling, Vladivostok State University of Economic and Service (VVSU), Vladivostok, 690014, Russian Federation; Department of Applied Mathematics, Mechanics, Controlling and Software, Far Eastern Federal University, Vladivostok, 690091, Russian Federation; Email: rorogulin4@rambler.ru

Sergei Shlykov: Capital Construction and Reconstruction Office, Kuban State Technological University, Krasnodar, 350089, Russian Federation

Sergey Kondrashev: Department of Chemistry, I.M. Sechenov First Moscow State Medical University, Moscow, 119991, Russian Federation
}

ə Open Access. () 2022 S. Shlykov et al., published by De Gruyter. (cc) BY License

\section{Introduction}

Composite materials with polymer matrix are becoming more and more popular year by year, as they are used to create high-tech and household equipment [1, 2]. Due to their high strength-to-lightness ratio, viscoelastic polymers with reinforcing fibers make it possible to construct elements of water, aerospace, land, and air transport, also military equipment, residential buildings, or clothing [3-5].

At the same time, they are quite brittle when loads are applied and can crumble in the early stages. This also limits their use in installations where there is a need for vibration damping [1, 6-8]. High-amplitude repetitive vibrations can cause the appearance of microcracks, which significantly reduce the durability of structures and service life $[3,6,9]$. In the case of laminar composites, damage leads to oxidation of the layers, significantly worsening their parameters $[7,10]$. To improve the mechanical properties and the ability to withstand vibrations, materials capable of damping are used $[2,11,12]$.

Vibration damping is the effect that can be controlled actively (using the necessary sensors, mechanisms, compensators) or passively (when the material itself dissipates energy and has a high conversion efficiency) $[8,11,13]$. Therefore, in practice, passive control is used, which is due to implementation simplicity. There are several approaches to this effect, for example: ellipsometry, vibration isolation, structural stiffening and so on, but it is the latter method that is the most common. There are two types of its practical implementation: the addition of damping (to treat free damping) and high stiffness layers (to increase the shear deformation of the previous one) on structure surface or the introduction of damping material inside the composite $[3,8,12,14]$.

The search for the best fiber option is still ongoing. Recently, environmentally friendly, and natural fibers - vegetable fibers - have become more and more popular. Coconut, banana, flax, hemp, pineapple and abaca leaves, sugar cane, date, and other fibers are quite often used [1517]. Despite this, synthetic fibrils (carbon, fiberglass, or 
Kevlar) are most commonly used, which provide greater stability of polymer structures $[6,14,18]$. The effect of the state, size, length, and number of reinforcing fibers on the properties of composites is also studied [10,11]. Binding materials (silica nanoparticles, ferrum (III) oxide, carbon nanotubes, graphene nanoplates) are used to improve the mechanical parameters of the structures, which increase the bond between the fibers and polymers [7, 14, 15, 19].

During vibrations in the system, the transformation of the vibration energy into thermal energy is observed, which is associated with molecules' friction and the increase of their activity, which as a result can led to self-heating of the structure, which also affects the mechanical characteristics of the structure $[18,20]$.

There are many different matrices that are characterized by high viscosity and elasticity. Polymeric materials themselves have negligible damping abilities. Such molecules include epoxies, silicones, rubbers, plastics, vinyl esters, polyesters, polyacids and other substances [4, $15,16]$. To strengthen damping and increase the value of other mechanical parameters, combinations with fibers of different origin are created $[6,7,10]$.

The properties of matrix agglomerates with fiber have been extensively studied [21]. The combination of epoxy resin and glass fibers shows higher values of loss factor than for resin and linen fibers [11,22]. This indicates a lower damping capacity [16]. Adding high stiffening fibers to the matrix increases resistance to fatigue and improves impact strength of polymers but has almost no effect on vibration damping [23].

It is reported that in certain combinations (e.g., fibers with phenols) it is possible to cure the fibers from the polymer. It was later found out that this is affected by the degree of cross-linking and the hydrothermal treatment of the reinforced matrix [13, 24]. In order to overcome delamination of the damping layer from the whole composite, scientists investigated its impact, interlayer and corrosion characteristics. It has also been shown that the porous structure of the damping material optimizes the parameters of the final composite and improves the ability to dampen vibrations $[2,8]$.

Tests were carried out to determine the damping properties of polylactide composites with different kenaf fiber content. They showed that too high fiber fractions worsen the damping peak, relative to that of the pure material [15]. Fibrils of different sizes were used to analyze the effect of glass, carbon, basalt, polypropylene and Kevlar fibers on wood-polymer composites (WPCs). They found that the inclusion of long or continuous fibers in the composites leads to stronger mechanical characteristics (bending and tensile strength, impact toughness. In this case, mechani- cal properties rather than damping properties were studied, besides, the performance of WPCs differs from viscoelastic polymers [10]. A similar study was conducted with polypropylene composites reinforced with hemp or other types of natural fiber [11, 25, 26].

The level of acidity of the medium affects the damping coefficient. Materials at a pH greater than 7 are characterized by significantly higher damping abilities. It was suggested that jute fibers should be treated with an alkaline solution before aggregation with vinyl ester resin. However, as a result, the values of the damping factor dropped [15, 27].

Other researchers have tried to improve the performance in a different way - by increasing interfacial adhesion. There are different ways to treat fibers: acid treatment, oxidation in air or pure oxygen, electrodeposition of high molecular weight substances on the surface, introduction of nanoscale particles, compression formation and others $[11,17,21,28]$. It was shown that when the fibrils were soaked in epoxy-silicone oil, the ability to level vibrations improved [11, 29, 30]. Hemp fibers were treated with a silane derivative dissolved in a water-ethanol mixture. This increased the elastic modulus of the composites, but slightly reduced the tensile strength [17]. Most often, to increase the bond between the fibers and the matrix, various nanoscale substances (silicon, carbon modifications, iron compounds, etc.) are added to the composite $[11,14,27]$. Their presence improves thermomechanical properties, bending and shear strength, crack formation, thermal stability $[14,19]$. It is said that the introduction of nanoparticles and modifications can improve the damping properties of the composite $[20,29]$.

For macro-sized tubes, the effect of fillers on the ability to dampen vibrations was studied. For this purpose, polyurethane foam balls were used. It was shown that the damping coefficient significantly increased in comparison with the hollow tube with polymer composite reinforced with carbon fiber [23, 24, 31]. In addition, the damping performance depends on the filler fraction and distribution $[8,22]$. It is reported that fillers act as additional reinforcing elements and show good performance only at low damping rates [24, 28, 32].

The relevance of the work is justified by the need to find new aggregates of composite materials and fibers with good damping abilities. This article will be useful for those researching the effects of vibrations on viscoelastic polymers and finding methods to tackle them.

The scientific novelty of this work is the study of natural viscoelastic composites with different proportions of reinforcing fibers based on mechanical and dynamic characteristics in order to create and apply biodegradable viscoelastic composites in various fields. 


\subsection{Problem statement}

Viscoelastic composites are used in many fields of science and technology and are also found in everyday things. With this in mind, more and more people are trying to use natural substances in order not to harm nature. There is a need to determine a suitable amount of fiber that will provide the maximum possible vibration damping while minimally affecting other mechanical properties of the system and will be cost effective for practical applications.

Therefore, the purpose of this work is to find the most appropriate percentage of organic fiber - cellulose derived from corn stalks in a polylactic acid matrix, studying the changes in damping characteristics, tensile strength, bendtest.

To achieve this goal, it is necessary to solve a number of tasks:

1. Determine the methods and parameters for studying these characteristics;

2. Determine if the damping coefficient depends on other parameters;

3. Analyze the results and draw conclusions.

\section{Materials and methods}

This section describes the inputs to be used as well as briefly describes the methods on which the research is based which consist of obtaining cellulose fibrils, producing reinforced composites, obtaining samples and determining mechanical properties. The methodology includes mechanical bend and tear tests on composite properties to determine the dynamic characteristics.

The international standard used to prepare the samples was ISO 6721-3:2021 Plastics - Determination of dynamic mechanical properties - Part 3: Flexural vibration Resonance-curve method. This standard specifies a bending vibration method based on resonance curves to determine the complex elastic modulus $E^{\star} f$ of homogeneous plastics and the damping properties of laminates designed for acoustic insulation, such as systems consisting of a metal sheet covered with a damping plastic layer, or multilayer systems consisting of two layers of sheet metal with an intermediate plastic layer.

\subsection{Materials}

Cellulose was extracted from corn stalks obtained from the Naturovo Agrofabrika farm. Chemically pure polylactic acid was purchased from Komponent-Reactiv LLC. Reagents and equipment are presented by the laboratory of the I.M. Sechenov First Moscow State Medical University

\subsection{Method for producing cellulose fibrils}

Corn stalks were manually cut into $4-5 \mathrm{~cm}$ lengths and dried at $80^{\circ} \mathrm{C}$ for 2 hours in an Ecocell 55 - ECO line laboratory dryer (BMT Medical Technology s.r.o., Czech Republic). After that, they were subjected to the action of water steam at $220^{\circ} \mathrm{C}$ for 5 minutes in a 10-liter digester with a paddle stirrer KPP-00 (Penza Food Group, the Russian Federation). The resulting mass was treated with a $20 \% \mathrm{NaOH}$ solution at $80^{\circ} \mathrm{C}$ for 1 hour. After that, the clot was thoroughly washed with tap water until discoloration, dried in the air at room temperature for 5 hours, and sieved on a sieve analyzer A12 (Vibrotechnik LLC, the Russian Federation) with a pore diameter of 0.25-10 $\mathrm{mm}[25,27,29]$.

\subsection{Method for producing reinforced composites}

To make the materials, polylactic acid was mixed with a certain amount of fibrils: $0-30 \%$ in $5 \%$ intervals. The suspension was then placed between steel plates for 3 hours, applied pressure of $0.5 \mathrm{MPa}$, at $35^{\circ} \mathrm{C}$. For complete polymerization of the composites, they were left at room temperature for two weeks $[6,30]$. The thickness of the films increases with increasing amount of fiber and is (in microns): $118.4 \pm 11.3 ; 121.1 \pm 9.7 ; 122.0 \pm 10.4 ; 123.5 \pm 8.7 ; 122.4 \pm 14.0$; $126.7 \pm 12.2 ; 127.0 \pm 14.4$.

\subsection{Method for obtaining samples}

To study the properties of the obtained composites, 5 square-shaped specimens with an area of $400 \mathrm{~mm}^{2}$ were cut from each material. The total number of experimental models is 35 pieces.

\subsection{Methods for determining mechanical properties}

Bend and tear tests were performed on the HD-B604-S Universal Testing Machine (HAIDA EQUIPMENT CO., LTD, China) under standard conditions. The speed of the measuring slide was $0.8 \mathrm{~mm} / \mathrm{min}$. 
Dynamic characteristics were studied on a benchtop dynamic mechanical analyzer DMA 25 (01dB-Metravib, France) at a temperature of 40 to $90^{\circ} \mathrm{C}$, at a rate of 2.5 $\mathrm{deg} / \mathrm{min}$, with a frequency of $1 \mathrm{~Hz}[26,30,31]$.

The calculation of indicators is carried out automatically by formulas:

$$
\begin{gathered}
E^{\prime}(\omega)=E^{0}\left[1+\omega^{2} \sum_{i} \alpha_{i} \frac{\omega^{2}-\omega_{i}^{2}+\left(2 \varsigma_{i} \omega_{i}\right)^{2}}{\left(\omega^{2}-\omega_{i}^{2}\right)^{2}+\omega^{2}\left(2 \varsigma_{i} \omega_{i}\right)^{2}}\right] \\
E^{\prime \prime}(\omega)=E^{0} \omega \sum_{i} \alpha_{i} \frac{\omega_{i}^{2}\left(2 \varsigma_{i} \omega_{i}\right)}{\left(\omega^{2}-\omega_{i}^{2}\right)^{2}+\omega^{2}\left(2 \varsigma_{i} \omega_{i}\right)^{2}}
\end{gathered}
$$

where $E^{0}$ - equilibrium elasticity constant, which refers to the viscoelastic material relaxation function:

$$
E^{0}=\lim _{t \rightarrow \infty} G(t)
$$

$\alpha_{i}, \varsigma_{i}, \omega_{i}$ - are three independent parameters of the minioscillator [4].

In a one-dimensional relaxation test, the material is subjected to a sudden strain that is kept constant over the duration of the test, and the stress is measured over time. The initial stress is due to the elastic response of the material. Then, the stress relaxes over time due to the viscous effects in the material. Typically, either a tensile, compressive, bulk compression, or shear strain is applied. The resulting voltage-time dependence data can be fitted by a series of equations, called models and defined as:

$$
G(t)=E_{\infty}+\sum_{i=1}^{N} G_{i} \exp \left(\frac{-t}{\tau_{i}}\right)
$$

where $E_{\infty}$ is the long-term modulus once the material is totally relaxed, $\tau_{i}$ are the relaxation times, the higher their values, the longer it takes for the stress to relax.

The damping factor is determined by the formula [32]:

$$
\tan (\delta)=\frac{E^{\prime \prime}}{E^{\prime}}
$$

where $E^{\prime}$ is the real part of the accumulation modulus, representing the elastic properties of the material, $E^{\prime \prime}$ - the loss modulus that characterizes the hysteretic damping properties.

The storage modulus gives information about the amount of structure present in a material. It represents the energy stored in the elastic structure of the sample. If it is higher than the loss modulus the material can be regarded as mainly elastic, i.e., the phase shift is below $45^{\circ}$. The loss modulus represents the viscous part, or the amount of energy dissipated in the sample. The 'sum' of loss and storage modulus is the so-called complex modulus [31, 32].
The accumulation and loss modulus in viscoelastic materials measure the stored energy, representing the elastic portion, and the energy dissipated as heat, representing the viscous portion.

The damping factor is the basic parameter for determining the damping capability of a viscoelastic material, where the higher the loss factor of the material, the higher the energy dissipation that can be expected from the material during harmonic deformation. For a material with a greater than 1 energy-dissipating, viscous component of the complex modulus prevails [23].

To determine the effect of the number of fibrils on composites' performance, the coefficient $C$ is calculated:

$$
C=\frac{\left(\frac{E_{C}^{\prime}}{E_{P L A}^{\prime}}\right) \operatorname{comp}}{\left(\frac{E_{c}^{\prime \prime}}{E_{P L A}^{\prime \prime}}\right) m a t r}
$$

where index $C$ corresponds to the dynamic indicators for cellulose $\frac{E_{C}^{\prime}}{E_{P L A}^{\prime}}$ with the real part being the accumulation modulus, and $\frac{E_{C}^{\prime \prime}}{E_{P L A}^{\prime \prime}}-$ loss modulus with hysteretic damping properties together with polylactic acid PLA in the glassy and rubbery regions $[16,19]$.

The coefficient $C$ shows the effectiveness of the influence of the filler on the elastic modulus of composites.

\section{Results and discussion}

Figure 1 shows the dependence of composites' mechanical properties on the amount of reinforcing fibers. The strength and flexibility of the materials decreases with the growth of the fibrils content. With an increase in the number of cellulose, one can observe lower rate of decline in strength and a slight increase in flexibility. This may be due to an increase in the amount of lignin in the matrix composition.

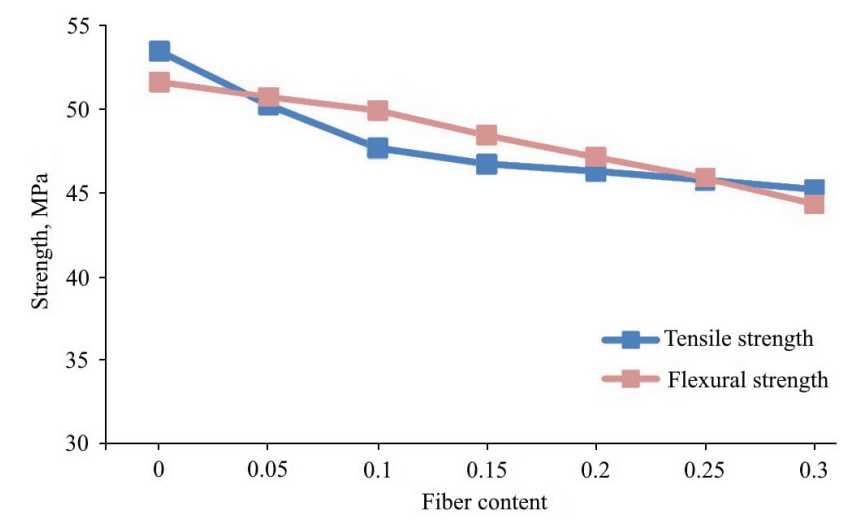

Figure 1: Plots of the flexural and tensile strength dependence on the number of cellulose fibers 

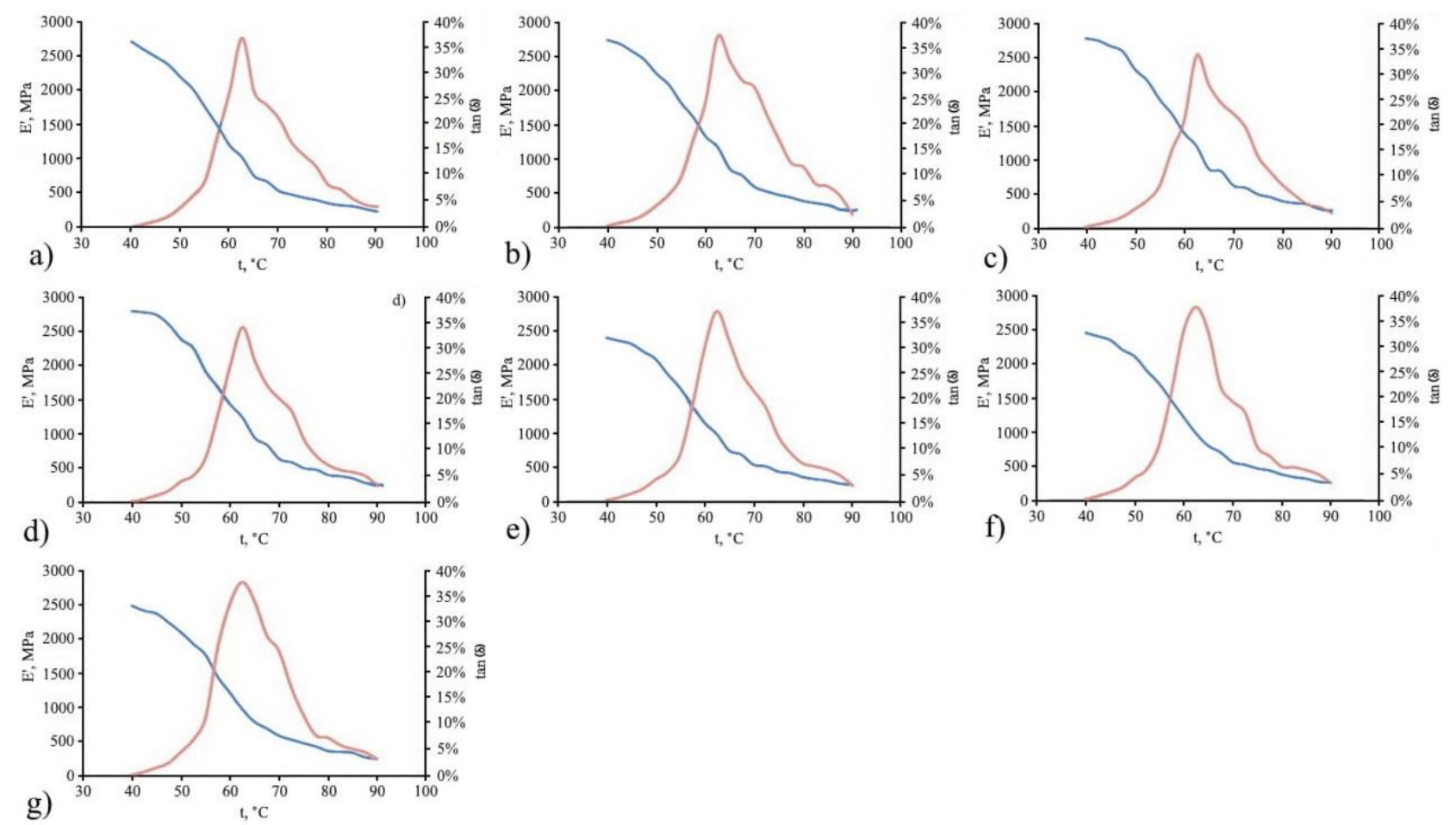

Figure 2: Plots of dependence of accumulation modulus $E^{\prime}$ and damping factor $\tan (\delta)$ of polylactic acid composites on the current temperature for different amounts of reinforcing cellulose fiber: a) $0 \%$; b); $5 \%$; c) $10 \%$; d) $15 \%$; e) $20 \%$; f) $25 \%$; g) $30 \%$

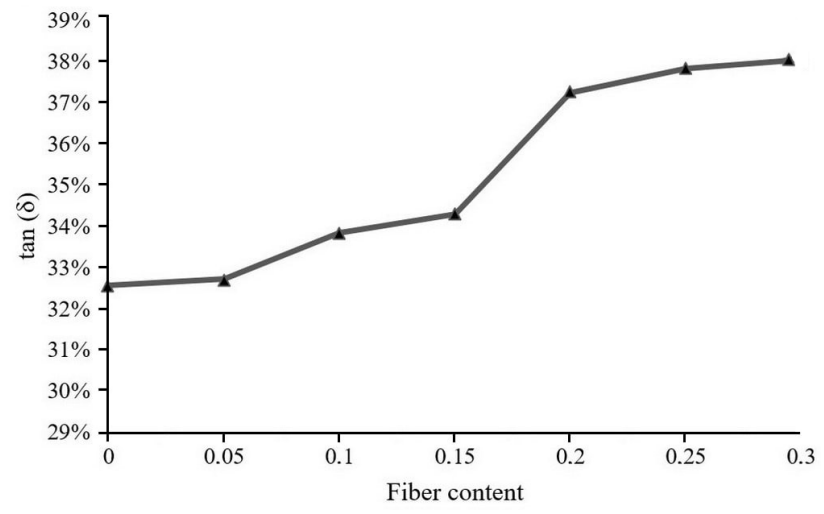

Figure 3: Dependence of peak value of damping factor $\tan (\delta)$ on the amount of cellulose fiber in the matrix

Figure 2 shows that for the accumulation modulus one can observe a decrease in values with increasing temperature regardless of the presence of fibrils. At low cellulose content, the decrease of $E^{\prime}$ is more rapid. In addition, with the increase of fibers in the composite, one can see the sigmoidal formation of this dependence. The maximum number of the accumulation modulus increases with increasing cellulose percentage: 2289-2503 MPa. The peak values of the damping coefficient determine the glass transition temperature of the composite. In all variants $\mathrm{T}_{g}$ is

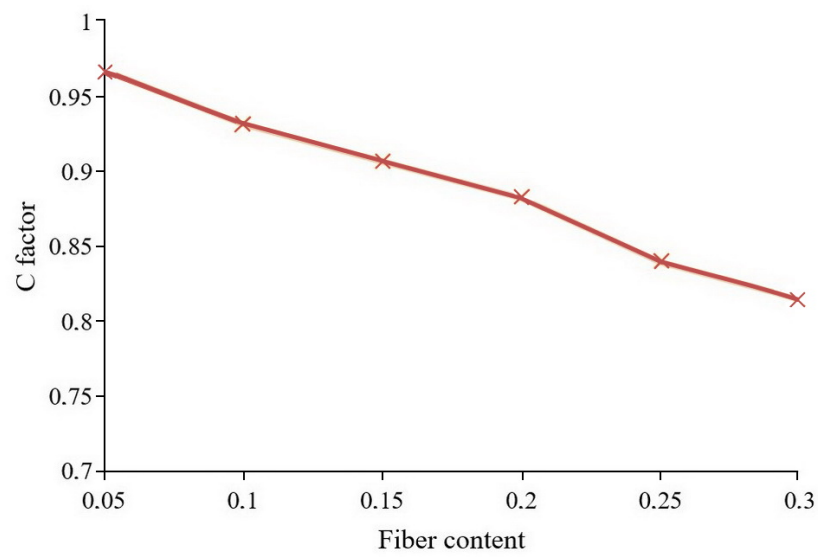

Figure 4: Dependence of the influence factor of fibers on their quantity in composite matrices

$62.5^{\circ} \mathrm{C}$, it follows that it does not depend on the amount of contributed fiber. However, as the number of fibrils increases, the width of the peak increases, which indicates an increase in the damping capacity at approximate temperatures.

Figure 3 shows the dependence of the maximum value of the damping factor on the amount of reinforcing fiber. The lowest value at the glass transition temperature is $32.56 \%$ (in the absence of fiber), and the highest is 38.06\% 


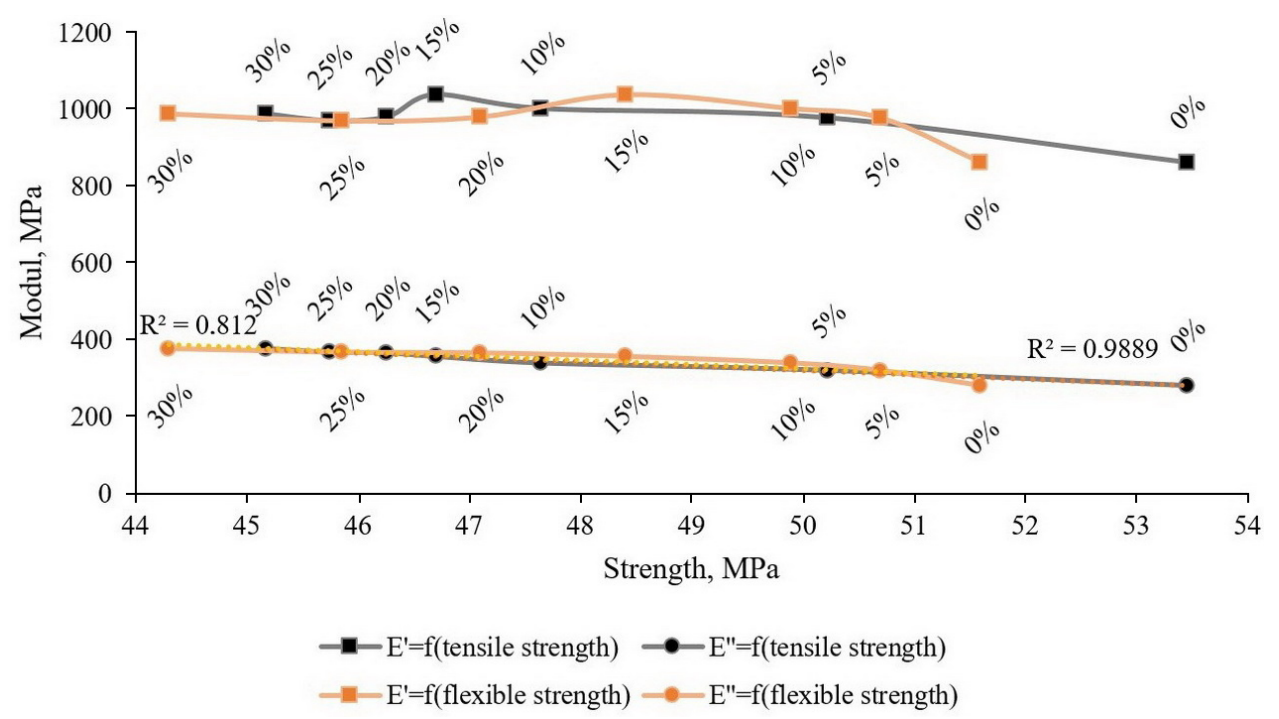

Figure 5: Dependence of dynamic moduli (at the temperature of the peak damping coefficient) on the mechanical parameters

(with the inclusion of $30 \%$ of reinforcing fiber in the composite). It should be noted that the difference in the peak value of $\tan (\delta)$ at $25 \%$ and $30 \%$ cellulose is insignificant and is only $0.24 \%$.

Figure 4 clearly shows that increasing the proportion of reinforcing fiber affects composite performance, which confirms all the results obtained.

To determine dependence of damping on mechanical parameters, the dependence of accumulation and losses modulus on tensile and flexural strength was plotted.

It follows from Figure 5 that an increase in strength characteristics leads to a drop in dynamic characteristics. The accumulation modulus does not correlate with flexural and tensile strength, while the loss modulus shows a strong linear dependence on tensile strength and a weak dependence on flexural. Since composites' damping capacity is mainly determined by the modulus $E^{\prime}$, then the change in mechanical factors during the addition of reinforcing fiber will affect the damping factors.

The mechanical characteristics were determined by Mihalic et al. using cellulose and polypropylene matrix. An increase in the proportion of cellulose in a composite leads to a decrease in the modulus of strength. Since it depends on the tensile strength, it indicates a decrease in its value. The results obtained in the present study are similar: the more fibers in the composite, the lower the strength value [20].

In [21] it is reported that the presence of fibrils increases the maximum tensile strength by $11 \%$ and flexural by $22 \%$ when adding $2 \%$ of carbon nanotubes to the epoxy matrix. Whereas in the present experiment, the strength and flexibility of the matrix decreases with increasing amount of cellulose. Zhang et al. studied the influence of quantitative and qualitative composition of polyethylene composites on these indicators. Irrespective of the fiber type, the tensile strength increased rapidly with an increase in its quantity, while the flexural strength increased only slightly. This may be due to uneven distribution of fibers in the composite, insufficient length, or differences in the effect of cellulose fibrils on the polylactate [10].

The paper [28] states that with the increase of lignin amount in the composition of polylactic acid-cellulose composite, the mechanical indicators of matrix increase (by $1.4-27.92 \%$ depending on the ratio matrix: cellulose: lignin $=11.5: 1: 1.4-88.1: 1: 10.9$ ), while in the present study they decreased. Perhaps lignin impurities in cellulose increase the strength characteristics and the cellulose itself increases the dynamic characteristics, because the current study values are slightly different: 5.83:1.5:1-47.5:1.5:1.

Chen et al. show that when polypropylene is reinforced with Ramine fiber, the values of tensile and flexural strength increase by $21 \%$ and $27 \%$ respectively. They obtained an increase in the damping coefficient when the amount of fiber in the composite is increased. That is, the ramine fiber is able to increase the mechanical and dynamic characteristics of the materials, while cellulose increases only the latter [11]. Cichosz et al. investigated the effect of different amounts and degrees of processing of cellulose fibrils on the mechanical and dynamic abilities of ethylenenorbornene polymer. It is said that the presence of $35 \%$ of fibers reduces the tensile strength by more than $50 \%$. In the present experiment, there was a decrease of only $15 \%$. In addition, materials with $14 \%$ untreated pulp show maximum values $E^{\prime}=0.5 \mathrm{MPa}, E^{\prime \prime}=0.3 \mathrm{MPa}$. Aggregates 
of polylactic acid and cellulose show significantly higher values, which indicates a significant level of damping and strength retention of the material [24]. The inclusion of 30\% of cellulose nanofibers in the polyethylene glycol matrix leads to a significant increase in the accumulation modulus, more than twofold. Whereas this index for polylactic acid increased by only $9 \%$ in the present work. This may be due to the presence of good elasticity values for it [30].

The effect of carbon fibers on the damping ability of epoxy composites was investigated by Fan et al. They showed a significant increase in the loss modulus after crosslinking the damping and elastic layers. In the present experiment, the presence of fibers also increases the value of $\tan (\delta)$, although a different method of creating composites was used [7]. Muthui et al. studied viscoelastic properties of polylactic acid. It was shown that the maximum value of $E^{\prime}$ was $2250 \mathrm{MPa}$, and $E^{\prime \prime}$ - approx. $360 \mathrm{MPa}$. The present study shows that in the absence of fibers, the maximum accumulation modulus number is $2289 \mathrm{MPa}$ and loss modulus is $280 \mathrm{MPa}$. Perhaps the material thickness influences the obtained values, because in the present study, composites of 107.1-141.4 $\mu \mathrm{m}$ were used, and Muthui et al. used $20 \mu \mathrm{m}$ [26].

Similar work was done by Arteaga-Ballesteros et al. They investigated the effect of $1 \%, 3 \%$ and $5 \%$ of cellulose on the properties of the polylactate matrix. Their resulting tensile strengths are 67, 66, 62 and $57 \mathrm{MPa}$ for pure matrix and composites in order of increasing fiber fraction. Broader ranges were used in the present study, so it is possible to compare only the first and the last value. They are significantly different: 53.45 and $50.22 \mathrm{MPa}$ for the present study material. It is possible that the mechanical performance depends on the degree of acid polymerization, so it is necessary to study this direction in more detail. The glass transition temperature of composites established by Arteaga-Ballesteros et al. is $62-65^{\circ} \mathrm{C}$ and it decreases with the addition of fiber, when in the present experiment the temperature is $62.5^{\circ} \mathrm{C}$ for all samples [33].

Poletto reports that the inclusion of wood flour fibers in polystyrene-co-maleic anhydride affects the material, as evidenced by the decrease in $\mathrm{C}$-factor values, which is a similar result to the present study [19].

\section{Conclusions}

Lactic acid polymer and cellulose fibers were chosen as environmentally friendly materials to create composites and test fibers' effect on the materials' viscoelastic properties. For comparative parameters, it was decided to use flexural and tensile strength, modulus of accumulation and loss, factor $C$. It was found that the presence of $30 \%$ of cellulose causes a drop in the mechanical properties of almost $15 \%$. The damping properties were studied using the ratio of the loss modulus to the accumulation modulus. In the course of increasing the number of fibers, an increase in the height and width of the graph of damping factor's dependence on temperature was observed. It stipulates the presence of not bad viscoelastic properties in wider temperature range, and also approximation of the loss modulus graph to the sigmoidal form. The obtained results are confirmed by the fall of the $\mathrm{C}$ coefficient. It was investigated that the values of the accumulation modulus corresponding to the glass transition temperature and the mechanical properties are not interdependent with the growth of the fibril fraction in the material. A linear correlation was found for loss modulus and tensile strength at this temperature with increasing amount of reinforcing fiber.

The research results can be applied to the creation of biodegradable viscoelastic composite materials capable of damping.

The application of this composite material is possible with laminated plastics for acoustic insulation, systems consisting of sheet metal and also covered with a damping layer of plastic or multilayer structures consisting of two sheets of metal with an intermediate layer of plastic.

Work in this area can be continued by studying composites at different vibration amplitudes and thicknesses of composite films. It is also necessary to study in more detail the influence of the lignin in the composition of the fibers on materials' performance. To improve the mechanical properties of viscoelastic materials, it is necessary to conduct research on creating composites with hybrid fibers and study their effect on damping.

Funding: This research did not receive any specific grant from funding agencies in the public, commercial, or notfor-profit sectors.

Authors contribution: All authors contributed equally to the experimentation, read and approved the final manuscript.

Conflict of interests: Authors declare that they have no conflict of interests.

Data Availability: Data will be available on request. 


\section{References}

[1] Varghese AJ, Ronald BA. Low velocity impact, fatigue and Viscoelastic behaviour of carbon/E-glass intra-ply fibre-reinforced Nano-silica toughened epoxy composite. Silicon. 2021;13:1655 61.

[2] Zheng C, Duan F, Liang S. Manufacturing and mechanical performance of novel epoxy resin matrix carbon fiber reinforced damping composites. Compos Struct. 2021;256:113099.

[3] Ni NN, Wen YF, He DL, Yi XS, Guo MC, Xu YH. Process on the research of structure-damping composites. J Mater Eng. 2015;43(6):90-101.

[4] Liu Q. Damping mathematical modelling and dynamic responses for FRP laminated composite plates with polymer matrix. Curved Layer Struct. 2018;5(1):35-42.

[5] Ralph C, Silberstein M, Thakre PR, Singh R. Mechanics of Composite and Multi-functional Materials, Volume 7. Proceedings of the 2015 Annual Conference on Experimental and Applied Mechanics. Springer, 2015.

[6] Assarar M, Zouari W, Ayad R, Kebir H, Berthelot JM. Improving the damping properties of carbon fibre reinforced composites by interleaving flax and viscoelastic layers. Compos, Part B Eng. 2018;152:248-55.

[7] Fan W, Li JL, Chen L, Wang H, Guo DD, Liu JX. Influence of thermooxidative aging on vibration damping characteristics of conventional and graphene-based carbon fiber fabric composites. Polym Compos. 2016;37(9):2871-83.

[8] Salahuddin B, Mutlu R, Baigh TA, Alghamdi MN, Aziz S. Selfreinforced nylon 6 composite for smart vibration damping. Polymers. 2021;13(8):1235.

[9] Bendine K, Satla Z, Boukhoulda FB, Nouari M. Active vibration damping of smart composite beams based on system identification technique. Curved Layer Struct. 2018;5(1):43-8.

[10] Zhang J, Li Y, Xing D, Wang Q, Wang H, Koubaa A. Reinforcement of continuous fibers for extruded wood-flour/HDPE composites: effects of fiber type and amount. Constr Build Mater. 2019;228:116718.

[11] Chen D, Pi C, Chen M, He L, Xia F, Peng S. Amplitudedependent damping properties of ramie fiber-reinforced thermoplastic composites with varying fiber content. Polym Compos. 2019;40(7):2681-9.

[12] Assarar M, Zouari W, Sabhi H, Ayad R, Berthelot JM. Evaluation of the damping of hybrid carbon-flax reinforced composites. Compos Struct. 2015;132:148-54.

[13] Tang X, Yan X. A review on the damping properties of fiber reinforced polymer composites. J Ind Text. 2020;49(6):693-721.

[14] Vakilifard M, Mahmoodi MJ. Dynamic moduli and creep damping analysis of short carbon fiber reinforced polymer hybrid nanocomposite containing silica nanoparticle-on the nanoparticle size and volume fraction dependent aggregation. Compos, Part B Eng. 2019;167:277-301.

[15] Saba N, Jawaid M, Alothman OY, Paridah MT. A review on dynamic mechanical properties of natural fibre reinforced polymer composites. Constr Build Mater. 2016;106:149-59.

[16] Ornaghi HL Jr, Neves RM, Monticeli FM, Almeida JH Jr. Viscoelastic characteristics of carbon fiber-reinforced epoxy filament wound laminates. Compos Commun. 2020;21:100418.
[17] Sepe R, Bollino F, Boccarusso L, Caputo F. Influence of chemical treatments on mechanical properties of hemp fiber reinforced composites. Compos, Part B Eng. 2018;133:210-7.

[18] Katunin A. Criticality of the self-heating effect in polymers and polymer matrix composites during fatigue, and their application in non-destructive testing. Polymers. 2019;11(1):19.

[19] Poletto M. Mechanical, dynamic mechanical and morphological properties of composites based on recycled polystyrene filled with wood flour wastes. Maderas Cienc Tecnol. 2017;19(4):43342.

[20] Mihalic M, Sobczak L, Pretschuh C, Unterweger C. Increasing the impact toughness of cellulose fiber reinforced polypropylene composites-influence of different impact modifiers and production scales. J Compos Sci. 2019;3(3):82.

[21] Ofoegbu SU, Ferreira MG, Zheludkevich ML. Galvanically stimulated degradation of carbon-fiber reinforced polymer composites: a critical review. Materials. 2019;12(4):651.

[22] Binu PP, George KE, Vinodkumar MN. Effect of nanoclay, Cloisite15A on the mechanical properties and thermal behavior of glass fiber reinforced polyester. Procedia Technol. 2016;25:84653.

[23] Chawla K, Ray-Chaudhuri S. A study on damping ratio of EPS foam filled CFRP composite tubes. Curved Layer Struct. 2020;7(1):17885.

[24] Cichosz S, Masek A, Rylski A. Cellulose modification for improved compatibility with the polymer matrix: mechanical characterization of the composite material. Materials. 2020;13(23):5519.

[25] Cheşcă AM, Tofănică BM, Puiţel AC, Nicu R, Gavrilescu D. Environmentally friendly cellulosic fibers from corn stalks. Environ Eng Manag J. 2018;17(7):1765-71.

[26] Muthui ZW, Kamweru PK, Nderitu FG, Hussein SA, Ngumbu R, Njoroge GN. Polylactic acid (PLA) viscoelastic properties and their degradation compared with those of polyethylene. Int J Phys Sci. 2015;10(21):568-75.

[27] Heinze T, El Seoud OA, Koschella A. Production and characteristics of cellulose from different sources. Cellulose Derivatives. Cham: Springer; 2018. p. 1-38.

[28] Sousa S, Costa A, Silva A, Simões R. Poly (lactic acid)/cellulose films produced from composite spheres prepared by emulsionsolvent evaporation method. Polymers. 2019;11(1):66.

[29] Boufi S, Chaker A. Easy production of cellulose nanofibrils from corn stalk by a conventional high speed blender. Ind Crops Prod. 2016;93:39-47.

[30] Moberg T, Tang H, Zhou Q, Rigdahl M. Preparation and viscoelastic properties of composite fibres containing cellulose nanofibrils: formation of a coherent fibrillar network. J Nanomater. 2016;2016:9569236.

[31] He X, Qu M, Shi X. Damping properties of ethylene-vinyl acetate rubber/polylactic acid blends. J Mater Sci Chem Eng. 2016;4(3):15

[32] Gröhlich M, Lang A, Böswald M, Meier J. Viscoelastic damping design-Thermal impact on a constrained layer damping treatment. Mater Des. 2021;207:109885.

[33] Arteaga-Ballesteros BE, Guevara-Morales A, San Martín-Martínez E, Figueroa-López U, Vieyra H. Composite of polylactic acid and microcellulose from kombucha membranes. e-Polymers. 2021;21(1):15-26. 